\title{
Complications in cell-surface labelling by biotinylation of Candida albicans due to avidin conjugate binding to cell-wall proteins
}

\author{
James Masuoka, ${ }^{1}$ Lori N. Guthrie ${ }^{1}$ and Kevin C. Hazen ${ }^{1,2}$ \\ Author for correspondence: James Masuoka. Tel: +1 434243 3744. Fax: +1 4349249312. \\ e-mail:jm2n@virginia.edu
}

1,2 Departments of Pathology 1 and Microbiology2, University of Virginia Health System, Charlottesville, VA 22908, USA
Initial contact between the opportunistic fungal pathogen Candida albicans and host tissue occurs at the cell surface. Biotin derivatives have been used to label the cell-surface proteins of yeasts, with labelled proteins subsequently detected by avidin-reporter conjugates. Previous work has indicated that avidin can bind to $C$. albicans proteins in the absence of biotin, suggesting a possible host-cell-recognition mechanism by fungal cell-surface proteins. To investigate this mechanism, Western blots of proteins extracted from biotinylated and mock-treated cells were probed with avidin or modifiedavidin reagents. Each avidin reagent bound to cell-wall proteins extracted from non-biotinylated cells. Binding did not appear to be due to the lectin-like activity of the cell-wall proteins of $C$. albicans or to the presence of biotin in the sample itself. Binding was inhibited by added biotin, by the chaotrope KSCN and by $\mathrm{NaCl}$ in a concentration-dependent manner, although inhibition varied among the avidin conjugates tested. Thus, the non-specific binding of avidin to the cell-wall proteins of $C$. albicans appears to involve hydrophobic and electrostatic interactions, depending on the particular avidin species. These observations demonstrate potential pitfalls in the use of avidin-biotin complexes to identify cell-surface molecules and could provide insights into protein-protein interactions at the $\boldsymbol{C}$. albicans cell wall.

Keywords: yeast, adhesion

\section{INTRODUCTION}

Candida albicans is found in the normal fungal microbiota of humans. Although usually an obligate commensal, this organism is opportunistically pathogenic and has become an increasing problem over the past two decades, particularly in immunocompromised patients. Candida species account for nearly $80 \%$ of nosocomial fungal infections, of which nearly $60 \%$ are due to $C$. albicans alone (Beck-Sagué et al., 1993; Sternberg, 1994). Colonization by C. albicans, initiated by the adhesion of the fungal cell surface to the host tissue, occurs early in pathogenesis. Because of this, there has been interest in the characterization of the cell-wall proteins of $C$. albicans in general, and cell-surface proteins in specific,

Abbreviations: HRP, horseradish peroxidase; LYT, supernatant produced following treatment with lyticase; SDS extract, supernatant produced following SDS treatment of disrupted cell pellet; SUP, supernatant produced following cell disruption by glass beads. since the late 1960's [for reviews see Cassone (1989), Odds (1988) and Reiss et al. (1992)].

Our work focuses on one particular characteristic of the cell surface that influences C. albicans pathogenesis, namely cell-surface hydrophobicity, and on its influence on the onset of disease. A current model states that cellsurface hydrophobicity in C. albicans is due to the presence of hydrophobic proteins at the cell surface (Hazen \& Hazen, 1992). However, in order for the cells to be observed as hydrophobic their proteins must be exposed at the surface. This exposure occurs via changes in the conformation of surface fibres (Hazen \& Hazen, 1992, 1993). We are therefore interested in labelling cellsurface groups to identify hydrophobic cell-wall proteins, and to identify fibril proteins or glycans potentially involved in hydrophobic protein exposure.

Previous labelling studies have identified differences in the cell-surface proteins of hydrophobic and hydrophilic cells, using iodination in the labelling procedure (Hazen \& Hazen, 1992, 1993; Hazen et al., 1990). Although 
radioisotopic labelling was useful for analytical purposes, subsequent purification schemes were complicated by the presence of radioactive material. The use of reactive biotinyl derivatives and avidin conjugates for the non-radioactive detection of proteins and glycoconjugates on blots has been described (Bayer \& Wilchek, 1980; Bayer et al., 1987). These reagents were subsequently adapted for labelling the surface of intact mammalian (Hurley et al., 1985) and yeast cells (Alexandre et al., 2000; Casanova et al., 1992; Kandasamy et al., 2000; Marot-Leblond et al., 2000; Mrsǎ et al., 1997).

Our previous experience with avidin-biotin systems has involved using biotinylated antibodies and horseradishperoxidase(HRP)-conjugated avidin detectors in Western blots of the cell-wall proteins of C. albicans. We observed what appeared to be non-specific avidin binding in control lanes where the biotinylated antibody had been omitted. Although Duhamel \& Whitehead (1990) have discussed possible contributors to this apparently non-specific binding and methods for blocking it, we were more interested in identifying which particular interactions were involved in the binding of avidin to the cell-wall proteins of C. albicans. Understanding these interactions might provide insights into the binding of C. albicans to host tissues. For example, avidin is known to possess sequences similar to cellrecognition domains (Alon et al., 1990). If these domains are involved in the observed non-biotin-mediated binding, then the non-specific avidin binding in our control lanes may represent integrin-like proteins, such as the one described by Gale et al. (1996). If hydrophobic interactions are driving non-specific binding, then it might be possible to identify additional proteins that are responsible for cell-surface hydrophobicity (Singleton $e t$ al., 2001). Thus, proteins that are both biotinylated during surface labelling and bound by avidin in the absence of a biotin tag might prove relevant in the adhesion of C. albicans to host tissues.

This work presents a more detailed study of the binding of avidin to the cell-wall proteins of C. albicans, and a characterization of the interactions between the two components. Our characterization of the interactions between avidin and the cell-wall proteins of C. albicans considered avidin-biotin components, structural components (such as cell recognition sequences and glycosylation) and physico-chemical forces (electrostatic and hydrophobic).

\section{METHODS}

Reagents. HRP-avidin $\left(2.5 \mathrm{mg} \mathrm{ml}^{-1}\right), \quad \mathrm{HRP}-\mathrm{Z}$-avidin $\left(1.25 \mathrm{mg} \mathrm{ml}^{-1}\right)$, HRP-streptavidin $\left(1.25 \mathrm{mg} \mathrm{ml}^{-1}\right)$ and mouseanti-biotin monoclonal antibody were purchased from Zymed Laboratories. HRP-ExtrAvidin $\left(2 \cdot 1 \mathrm{mg} \mathrm{ml}^{-1}\right)$ and gelatin (teleostean, no. G-7765) were purchased from Sigma. Based on information from the manufacturers, the molar ratio of HRP : avidin was $2: 1$. Sulfo- $N$-hydroxysulfosuccinimide-(biotinamido) hexanoate (sulfo- $N$-hydroxysulfosuccinimide-LCbiotin) was purchased from Pierce. All other chemicals were of reagent grade.
Cultures and growth conditions. C. albicans LGH1095 has been previously described (Hazen \& Hazen, 1987). Cultures were maintained as frozen stocks and were prepared for use by three passages in yeast nitrogen base (Difco) buffered to $\mathrm{pH} 7 \cdot 0$ with sodium phosphate and supplemented with $2 \%$ $(\mathrm{w} / \mathrm{v})$ glucose, as previously described (Hazen \& Hazen, 1987). Cultures were grown aerobically at $37^{\circ} \mathrm{C}$. The final passage culture volume was $500 \mathrm{ml}$.

Biotinylation. Biotinylation was carried out according to Mrsă et al. (1997). Cells were harvested by centrifugation and washed three times with cold, sterile distilled water; the cell pellet was divided in two. Both pellets were washed twice with buffer A (50 $\mathrm{mM} \mathrm{KPO}_{4}, \mathrm{pH} \mathrm{8.0)}$. One pellet was suspended in $10 \mathrm{ml}$ of buffer A (mock-treated); the other was suspended in $10 \mathrm{ml}$ buffer A containing $10 \mathrm{mg}$ sulfo- $N$-hydroxysulfosuccinimide-LC-biotin. Both the mock-treated and the treated sample were incubated on ice for $90 \mathrm{~min}$, with occasional inversion. The samples were then centrifuged for $5 \mathrm{~min}$ at $1500 \mathrm{~g}$. Both pellets were washed twice in buffer B $(50 \mathrm{mM}$ Tris, $\mathrm{pH} 7 \cdot 5 ; 50 \mathrm{mM} \mathrm{MgCl}_{2}$ ) followed by a final wash in buffer A.

Release and isolation of cell-wall proteins. Cell walls were prepared by glass-bead breakage, as modified from Hazen \& Cutler (1982). The cell pellets were re-suspended in $20 \mathrm{ml}$ buffer $\mathrm{A}$ and $5 \mathrm{ml}$ of the suspension was transferred to each of four $30 \mathrm{ml}$ Corex tubes containing $10 \mathrm{~g}$ of glass beads (Glasperlen; 0.45-0.5 mm diameter; B. Braun Instruments). The tubes were subjected to alternating $15 \mathrm{~s}$ cycles of vortex mixing and ice incubation until cell breakage, determined microscopically, reached $80-90 \%$. Corresponding supernatants were removed and combined. The glass beads were washed three times with buffer A and the washes were added to their respective supernatants. Cell walls were pelleted by centrifugation $(10 \mathrm{~min}$ at $3000 \mathrm{~g})$ and the supernatant (SUP) was removed and reserved.

Proteins were extracted from isolated cell walls by sequential treatment with hot SDS and $\beta$-1,3-glucanase. The pellets were suspended in SDS sample buffer $(60 \mathrm{mM}$ Tris, pH $6.8 ; 2 \%$, $\mathrm{w} / \mathrm{v}, \mathrm{SDS} ; 0.5 \%, \mathrm{v} / \mathrm{v}, \beta$-mercaptoethanol) and heated at $95^{\circ} \mathrm{C}$ for $5 \mathrm{~min}$. Samples were centrifuged $(5 \mathrm{~min}$ at $2000 \mathrm{~g}$ ) and the supernatant (SDS extract) was removed and reserved. The SDS-extracted pellets were washed five times in buffer $\mathrm{B}$ and finally re-suspended in $3 \mathrm{ml} 50 \mathrm{mM} \mathrm{NaPO}$, $\mathrm{pH} 7 \cdot 4$. A protease inhibitor cocktail, consisting of PMSF (0.2 mM final concentration; Roche), EDTA (1 mM; Sigma), leupeptin ( $1 \mu \mathrm{M}$; Sigma), pepstatin A $(1 \mu \mathrm{M}$; Sigma) and 4-(2aminoethyl)-benzenesulfonyl fluoride ( $1 \mathrm{mM}$; Roche), was added to the suspension. A $\beta$-1,3-glucanase was added at 250 $\mathrm{U}(\mathrm{ml} \text { digest })^{-1}$ (Lyticase; Sigma, no. L-5263; $10000 \mathrm{U} \mathrm{ml}^{-1}$ stock) and the digests were incubated on a rotary mixer at $37^{\circ} \mathrm{C}$ overnight. The digests were centrifuged at $3000 \mathrm{~g}$ for $10 \mathrm{~min}$ and the supernatant (LYT) was removed and reserved. The protein concentration of all supernatants was determined by using the Coomassie Plus-200 assay (Pierce).

Electrophoresis and Western blotting. The cell-wall proteins released in each fraction were separated by SDS-PAGE $(12.5 \%$, w/v, acrylamide; Laemmli, 1970). Typically, $10 \mu \mathrm{g}$ total protein were loaded into each lane. Following electrophoresis, the proteins were transferred onto nitrocellulose (Osmonics) membranes using a Trans-Blot SD apparatus (Bio-Rad) run at a constant current $\left(1.0 \mathrm{~mA} \mathrm{~cm}^{-2}\right)$ for $1 \mathrm{~h}$, in

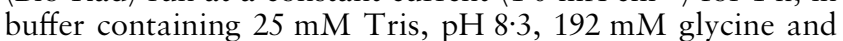
$20 \%$ (v/v) methanol (Towbin et al., 1979).

Membranes were blocked with TBST (50 mM Tris, pH 7.5; $150 \mathrm{mM} \mathrm{NaCl} ; 0 \cdot 1 \%, \mathrm{v} / \mathrm{v}$, Triton X-100) containing $4 \%$ 
(w/v) BSA, BLOTTO [PBS (10 $\mathrm{mM} \mathrm{NaPO}_{4}, \mathrm{pH} 7 \cdot 5 ; 150 \mathrm{mM}$ $\mathrm{NaCl}) ; 0 \cdot 1 \%, \mathrm{v} / \mathrm{v}$, Tween $20 ; 5 \%$, w/v, instant dry milk; Johnson \& Elder, 1983] or gelatin (from fish skin, 1\%, $\mathrm{v} / \mathrm{v}$, in PBS) for $1 \mathrm{~h}$ at room temperature. After blocking, membranes were incubated ( $1 \mathrm{~h}$ at room temperature) with the avidin conjugate (final concentration, $5 \mathrm{pmol}$ avidin $\mathrm{ml}^{-1}$ ) or with anti-biotin antibody $(1: 1000)$ in TBST $+1 \%(\mathrm{w} / \mathrm{v})$ BSA, BLOTTO or $1 \%$ gelatin. The membranes were washed three times $(10 \mathrm{~min})$ in $50 \mathrm{mM}$ Tris, $\mathrm{pH} 7 \cdot 5$. Avidin or antibody binding was detected by 3,3'-diaminobenzidine $+\mathrm{H}_{2} \mathrm{O}_{2}$ or by enhanced chemiluminescence (Leong et al., 1986). Blots were scanned on a flat-bed scanner and the image quality (contrast and brightness) was adjusted using Photoshop (version 6.0; Adobe) for reproduction. Apparent molecular masses were determined using a gel imager (AlphaImager 2000, Alpha Innotech) and its accompanying software, using the molecular mass markers as a standard curve.

Competition studies were carried out by mixing competitor (biotin, $\mathrm{KCl}, \mathrm{KSCN}$ or peptides) with the avidin conjugate (in TBST $+1 \%$ BSA, $15 \mathrm{~min}$ at room temperature) prior to membrane incubation. Synthetic peptides were provided by Dr Yahuan Lou (University of Texas, USA). Competitor concentrations were chosen based on published results that showed the inhibition of C. albicans cell binding or the disruption of protein-ligand interactions.

\section{RESULTS}

\section{Binding of avidin conjugates to cell-wall proteins of C. albicans}

HRP-Z-avidin bound to various proteins extracted from the cell wall of C. albicans (Fig. 1). Although the signal in the mock-treated samples was weaker than that in the biotinylated samples, the bands were clearly evident. The most prominent bands in the SUP fraction from mock-treated cells were approximately 116, 77, 53, 43 and $31 \mathrm{kDa}$ (Fig. 1). The most prominent bands in the SDS extracts were approximately 116, 77, 43 and $14 \mathrm{kDa}$. Weakly staining bands were also observed in the LYT extract (approx. 17 and $<13 \cdot 1 \mathrm{kDa}$, Fig. 1). Non-specific binding was also observed with samples from other yeast strains (C. albicans CAI4 and Saccharomyces cerevisiae X2180, not shown).

Replica blots were carried out and these were probed with HRP-streptavidin, HRP-ExtrAvidin and HRPavidin. Similar binding profiles to those of the mocktreated SDS extracts were observed with all avidin conjugates tested (Fig. 2, TBST lanes). The binding profiles of the SUP and LYT extract fractions were also the same, regardless of the avidin conjugate used (not shown). Control experiments, in which the membranes were probed with unconjugated HRP or with the colorimetric reagents alone, were negative (not shown). We tested the possibility that the observed binding was due to endogenous biotin, by probing blots of mocktreated cell-wall proteins with an anti-biotin antibody. A single intensely staining band $(116 \mathrm{kDa}$, apparent molecular mass) was observed in the extract from mocktreated cells (Fig. 2, right panel, far right). A few weakly staining bands were also visible, particularly after prolonged development. These bands may represent

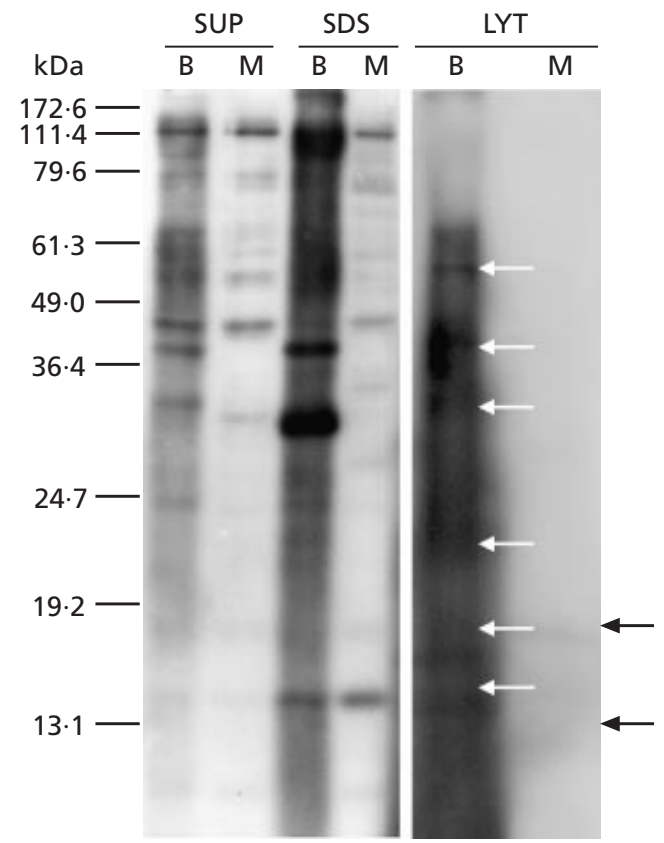

Fig. 1. Representative Western blot for the cell-wall proteins of C. albicans from biotinylated (B) or mock-treated (M) cells. SUP, supernatant fluid following cell disruption by glass beads; SDS, wall proteins extracted by treatment with hot SDS and $\beta$-mercaptoethanol; LYT, proteins extracted from SDS-treated cell walls by treatment with $\beta$-1,3-glucanase. Membranes were probed with HRP-Z-avidin and detected by enhanced chemiluminescence. Arrowheads highlight the weakly staining bands in the lyticase digests. Molecular mass markers are shown at the left of the image.

proteolytic products of the larger band or may be due to non-specific antibody binding.

\section{Experimental parameters affecting the observed non-specific binding}

Along with TBST + BSA, BLOTTO and gelatin are commonly used to block unoccupied membrane sites. Blots blocked with gelatin were identical to those blocked with TBST + BSA. BLOTTO almost completely blocked the binding of $\mathrm{Z}$-avidin, ExtrAvidin and avidin to the cell-wall proteins of C. albicans, even in biotinylated samples, but did not block the binding of streptavidin to proteins from mock-treated cells (Fig. 2). BLOTTO effectively blocked non-specific binding by the anti-biotin monoclonal antibody without significantly reducing binding to the biotinylated proteins (Fig. 2).

Blots of SDS extracts from both biotinylated and mocktreated cells $\left(10 \mu \mathrm{g}_{\text {lane }}{ }^{-1}\right)$ were probed with increasing dilutions of Z-avidin. In most cases, increased dilution of the avidin conjugate resulted in loss of signal in mocktreated lanes while still allowing visible staining of the biotinylated proteins. However, several bands in the mock-treated samples (apparent molecular masses of 116,33 and $27 \mathrm{kDa}$ ) were still visible at the highest Z- 

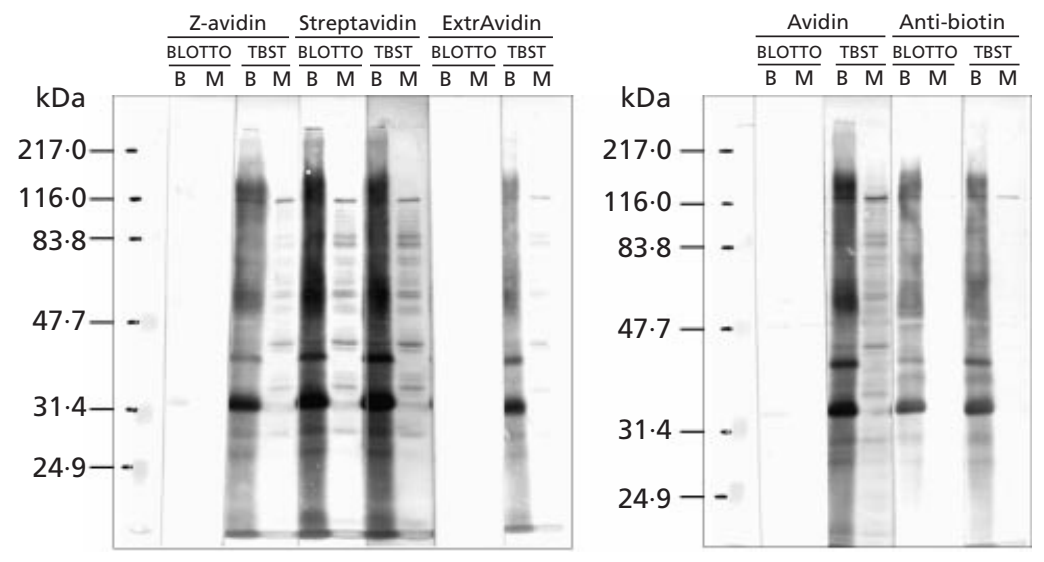

Fig. 2. Representative comparison of, and effect of blocking agent on, the binding of the different avidin conjugates to SDS extracts of $C$. albicans from biotinylated (B) or mock-treated (M) cells. Membranes were blocked with BLOTTO or TBST $+4 \%$ BSA and then probed with HRP-Z-avidin, HRPstreptavidin or HRP-ExtrAvidin (left panel), and HRP-Avidin or an anti-biotin antibody (right panel). Bound complexes were detected with 3,3'-diaminobenzidine $+\mathrm{H}_{2} \mathrm{O}_{2}$. Molecular mass markers are shown at the left of both images.

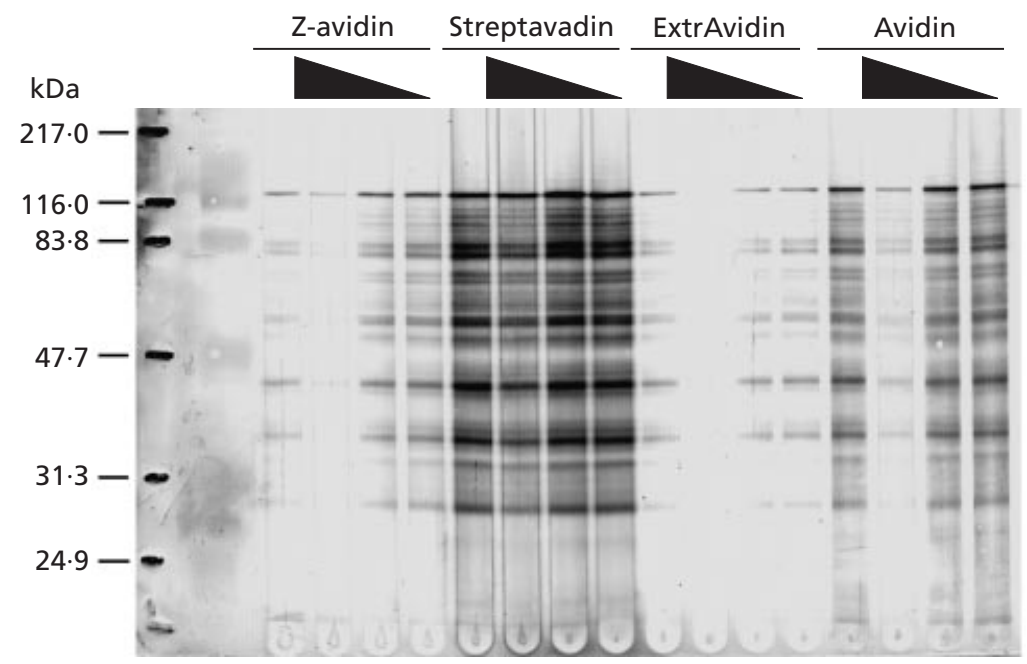

Fig. 3. Representative Western blot of $\mathrm{KSCN}$ inhibiting the binding of the different avidin conjugates to proteins from unlabelled cells. The first lane of each set of four contains no KSCN, the 'wedge' above the subsequent three lanes of each set represents the decreasing KSCN concentration. Bound avidin complexes were detected by 3,3'-diaminobenzidine $+\mathrm{H}_{2} \mathrm{O}_{2}$. Molecular mass markers are shown at the left of the image.

avidin dilution (1:160000). The $116 \mathrm{kDa}$ band maintained equivalent staining in treated and mock-treated samples, regardless of the Z-avidin dilution.

The converse experiment was carried out by probing twofold serial dilutions of SDS extract $(10-0 \cdot 3125 \mu \mathrm{g})$ with a constant dilution $(1: 5000)$ of $Z$-avidin. Again, there was a diminution in the signal for both the biotinylated and mock-treated samples. At $1.25 \mu \mathrm{g}$ of sample, most of the binding to unlabelled proteins was no longer apparent, whereas binding to biotinylated samples was still seen. However, even at $1.25 \mu \mathrm{g}$, a few of the non-specific bands were observed. In addition, the less intensely stained biotinylated bands began to be lost at the higher sample dilutions.

\section{Characterization of non-specific binding}

Several potential competitors were mixed, in parallel, with the avidin conjugates prior to probing of the blot. Binding by avidin, Z-avidin and ExtrAvidin to proteins from mock-treated cells was completely blocked by biotin down to a biotin concentration of $1 \mathrm{nM}$. Biotin inhibition of streptavidin binding was incomplete at $1 \mathrm{nM}$. Biotin also inhibited binding of the avidins to biotinylated proteins in a concentration-dependent manner (not shown). These results suggest that the site of binding to unlabelled proteins includes or is adjacent to the avidin-biotin binding site.

Binding by Z-avidin and ExtrAvidin was also completely inhibited by the addition of $1 \mathrm{M} \mathrm{NaCl}$. $\mathrm{NaCl}$ had only a slight effect on the binding of avidin and streptavidin. KSCN (1 M), which acts as a chaotrope (Hatefi \& Hanstein, 1969), inhibited the binding of $Z$-avidin and ExtrAvidin in a concentration-dependent manner (Fig. $3)$. There was also a slight concentration-dependent KSCN inhibition of avidin binding. Streptavidin binding was not inhibited by $1 \mathrm{M} \mathrm{KSCN}$.

Cell recognition (RGD) sequences have been shown to inhibit the binding of C. albicans cells to surfaces and to host cells (Klotz \& Smith, 1991; Nègre et al., 1994). Furthermore, streptavidin was shown to possess a similar sequence, RYD, which mimics the RGD sequence of fibronectin (Alon et al., 1990). RGD (20, 2.0 and $0.2 \mu \mathrm{g} \mathrm{ml}^{-1}$ ) and RGD-containing peptides from fibronectin $(1358 \mathrm{Fn}, 50 \mu \mathrm{M})$ or from laminin (1343Ln, $50 \mu \mathrm{M})$ were tested as potential inhibitors of avidin binding to the cell-wall proteins of C. albicans. None of the three peptides had an effect on binding by the avidin conjugates at the concentrations tested. 


\section{DISCUSSION}

Several groups have used biotin derivatives to label cell-surface proteins in yeasts (Alexandre et al., 2000; Casanova et al., 1992; Kandasamy et al., 2000; Marot-Leblond et al., 2000; Mrsǎ et al., 1997). Our results show that avidin can bind to the cell-wall proteins of C. albicans in the absence of a biotin tag. This nonbiotin-mediated binding may complicate data interpretation by leading to unwarranted conclusions of surface exposure. Supplemental data from biotin-labelled $S$. cerevisiae showed non-specific binding to SDS extracts of cell-wall proteins (I. Hagen and W. Tanner, personal communication). The relative signal strength of nonspecific to specific binding was comparable to the results presented in this study. Non-specific binding of streptavidin to human B cell and myeloid cell-surface proteins has also been previously reported (Cole et al., 1987). However, prior to this point, there have been no reports in the literature of non-specific binding by avidin to yeast cell-wall proteins or analyses of what mechanism is responsible for the interactions.

One study (Kandasamy et al., 2000) demonstrated another potential problem for biotin labelling. In this study, biotinylation was carried out in a Tris buffer, even though free amine species (e.g. Tris or glycine) will compete for the biotinylation reagent (Bayer \& Wilchek, 1980). Kandasamy et al. (2000) performed subsequent experiments using Western, Southern and Northern blots which clearly demonstrated that the proteins under investigation were expressed and present in the cell wall of C. albicans. Due to the biotinylation conditions, however, the conclusion that these proteins are present on the cell surface remains unsupported.

Marot-Leblond et al. (2000) reported the extraction of cellular components, and the separation of these components by hydrophobic-interaction chromatography, from unlabelled and biotinylated cells. Since only the results of the binding of streptavidin to proteins from biotinylated cells were reported, the reader is left to infer that no streptavidin staining occurred with extracts from unlabelled cells. They did, however, report the results of two important controls. Cell-wall protein biotinylation affected neither the protein extraction efficiency nor the hydrophobic-interaction chromatography profile (confirmed in our laboratory, unpublished results).

Casanova et al. (1992) showed that the biotinylation reagent does not cross the membrane into the cytoplasm. This confirmed for yeasts what had been seen previously for bovine leukocytes (Hurley et al., 1985). Thus, the presence of a signal in the bead-break supernatant (Fig. 1) was somewhat unexpected. As an alternative sample preparation technique, we prepared sphaeroplasts following biotinylation and compared the cell-wall fraction with the sphaeroplast lysate (see Casanova et al., 1992). Only a few distinct bands were observed in the lysate, confirming the observation made by Casanova et al. (1992). If the biotinylation reagent was crossing the cellular membrane and labelling the cytoplasmic pro- teins, a continuous smear of signal (the length of the blot) would be expected. Therefore, the observed signal in the SUP fraction is likely to be due to proteins loosely associated with the cell-wall matrix that are released by the breaking action itself (Pastor et al., 1984).

A simple overabundance of avidin does not explain the observed binding, since the concentration of the avidin conjugates was at or was below that suggested by the manufacturer and was similar to those found in the literature. The anti-biotin monoclonal antibody gave a single intense band in mock-treated cell samples (approx. 116 kDa, Fig. 2, right panel, far right). Because of this band, and other bands that were very faint, we must consider the possibility that some of the avidin conjugate binding to mock-treated cell-wall proteins is due to endogenous biotin. If avidin binding to unlabelled proteins is indeed due solely to endogenous biotin, showing a comparison of labelled and unlabelled proteins is even more of an imperative. However, based on the number of bands appearing in the lanes probed with the avidin conjugates, we think it likely that the observed avidin binding is due to interactions other than avidin-biotin.

Binding does appear to occur near the biotin site, because biotin inhibited the binding of avidin in a concentration-dependent manner (see Results). In addition, BLOTTO, used as a blocking agent, almost completely inhibited avidin binding to proteins from both biotinylated and mock-treated cells (Fig. 2). The concentration of biotin (from the dry milk) in BLOTTO $\left(0 \cdot 04-0 \cdot 10 \mathrm{nmol} \mathrm{ml}{ }^{-1}\right.$; Jensen, 1995) is two- to fourfold higher than the concentration of biotin-binding sites (0.005 nmol avidin $\mathrm{ml}^{-1}$ gives $0.02 \mathrm{nmol}$ biotin sites $\left.\mathrm{ml}^{-1}\right)$. This concentration is likely to be sufficient to approach saturation of the biotin-binding sites. The reason BLOTTO did not eliminate binding by streptavidin or the monoclonal antibody (Fig. 2 ) is less clear. The affinity of streptavidin $\left(4 \times 10^{-14} \mathrm{M}\right)$ is 67 -fold lower than that of avidin $\left(6 \times 10^{-16} \mathrm{M}\right)$. This lower affinity suggests that, during the probing step, streptavidin is more likely than the other avidins to release the biotin into solution and to be available for binding to the cell-wall proteins.

As noted above, avidin has been shown to possess affinity for other ligands. Avidin contains the RYD sequence that mimics the RGD sequence in the cell-wall recognition site of extracellular matrix proteins (Alon $e t$ al., 1990). The binding mediated by RYD is independent of the avidin-biotin interaction and thus represents another binding site. Studies by Gale et al. (1996) demonstrated that C. albicans possesses integrin-like proteins. Such integrin-extracellular matrix interactions might then explain some of the non-specific binding, although the specific extracellular matrix peptides tested here did not inhibit this binding activity (see Results). In addition, a lectin-like activity of the cell-wall proteins of C. albicans appears to be ruled out, since glycosylated (avidin) and unglycosylated (Z-avidin and streptavidin) forms bound in the absence of a biotin tag. 
Both $\mathrm{NaCl}$ and $\mathrm{KCSN}$, which interfere with electrostatic and hydrophobic interactions, respectively, were able to inhibit the binding of avidin, Z-avidin and ExtrAvidin to proteins from mock-treated cells. $\mathrm{NaCl}$ had a smaller effect on streptavidin and avidin binding to these proteins. KSCN did not inhibit binding by streptavidin, but was able to inhibit avidin binding at higher concentrations.

Because the biotin-labelling reagent is not membrane permeable, is not radioactive and labels under gentle and convenient conditions, it is a powerful tool for determining proteins at the fungal cell surface. It is these proteins that make and maintain first contact with the host tissues, making them important to the understanding of colonization and pathogenesis. Our results emphasize the necessity for an untreated control to aid in data interpretation. Proteins that produce Western blot signals in extracts from both labelled and unlabelled cells require additional tests (such as immunofluorescence microscopy) before they can be shown to be exposed on the cell surface. Our results further suggest that both the hydrophobic and electrostatic characteristics of the avidin conjugates seem to be involved in nonspecific binding, except in the case of streptavidin where only charge seems to play a role. Currently, we are extending our studies to carry out electrophoretic protein separation in two dimensions to more clearly identify those proteins which can be both labelled with biotin and bind to avidin (e.g. ExtrAvidin), i.e. proteins which may be responsible for cell-surface hydrophobicity. We will then apply these techniques to examine the differences in the expression of cell-surface proteins between hydrophobic and hydrophilic cells.

\section{ACKNOWLEDGEMENTS}

We thank Dr Yahuan Lou for providing synthesized extracellular matrix peptides, and Dr Widmar Tanner and Ilja Hagen for providing additional results from Saccharomyces cerevisiae biotinylation studies. We also thank Dr Elizabeth A. Machunis-Masuoka for her critical comments regarding the manuscript. This work was supported by PHS grants RO1AI43997 and RO1AI31048 from the National Institute of Allergy and Infectious Diseases.

\section{REFERENCES}

Alexandre, H., Blanchet, S. \& Charpentier, C. (2000). Identification of a 49-kDa hydrophobic cell wall mannoprotein present in velum yeast which may be implicated in velum formation. FEMS Microbiol Lett 185, 147-150.

Alon, R., Bayer, E. A. \& Wilchek, M. (1990). Streptavidin contains an RYD sequence which mimics the RGD receptor domain of fibronectin. Biochem Biophys Res Comm 170, 1236-1241.

Bayer, E. A. \& Wilchek, M. (1980). The use of the avidin-biotin complex as a tool in molecular biology. Methods Biochem Anal 26, 1-45.

Bayer, E. A., Ben-Hur, H. \& Wilchek, M. (1987). Enzyme-based detection of glycoproteins on blot transfers using avidin-biotin technology. Anal Biochem 161, 123-131.

Beck-Sagué, C. M., Jarvis, W. R. and the National Nosocomial Infections Surveillance System. (1993). Secular trends in the epidemiology of nosocomial fungal infections in the United States, 1980-1990. J Infect Dis 167, 1247-1251.

Casanova, M., Lopez-Ribot, J. L., Martinez, J. P. \& Sentandreu, R. (1992). Characterization of cell wall proteins from yeast and mycelial cells of Candida albicans by labelling with biotin: comparison with other techniques. Infect Immun 60, 4898-4906.

Cassone, A. (1989). Cell wall of Candida albicans: its function and its impact on the host. Curr Top Med Mycol 3, 248-314.

Cole, S. R., Ashman, L. K. \& Ey, P. L. (1987). Biotinylation: an alternative to radioiodination for the identification of cell surface antigens in immunoprecipitates. Mol Immunol 24, 699-705.

Duhamel, R. C. \& Whitehead, J. S. (1990). Prevention of nonspecific binding of avidin. Methods Enzymol 184, 201-207.

Gale, C., Finkel, D., Tao, N., Meinke, M., McClellan, M., Olson, J., Kendrick, K. \& Hostetter, M. (1996). Cloning and expression of a gene encoding an integrin-like protein in Candida albicans. Proc Natl Acad Sci US A 93, 357-361.

Hatefi, Y. \& Hanstein, W. G. (1969). Solubilization of particulate proteins and nonelectrolytes by chaotropic agents. Proc Natl Acad Sci US A 62, 1129-1136.

Hazen, K. C. \& Cutler, J. E. (1982). Optimal conditions for breaking medically important yeasts by an inexpensive and simple method. Mycopathologia 80, 113-116.

Hazen, K. C. \& Hazen, B. W. (1987). Temperature-modulated physiological characteristics of Candida albicans. Microbiol Immunol 31, 497-508.

Hazen, K. C. \& Hazen, B. W. (1992). Hydrophobic surface protein masking by the opportunistic fungal pathogen Candida albicans. Infect Immun 60, 1499-1508.

Hazen, K. C. \& Hazen, B. W. (1993). Surface hydrophobic and hydrophilic protein alterations in Candida albicans. FEMS Microbiol Lett 107, 83-88.

Hazen, K. C., Lay, J.-G., Hazen, B. W., Fu, R. C. \& Murthy, S. (1990). Partial biochemical characterization of cell surface hydrophobicity and hydrophilicity of Candida albicans. Infect Immun 58, 3469-3476.

Hurley, W. L., Finkelstein, E. \& Holst, B. D. (1985). Identification of surface proteins on bovine leukocytes by a biotin-avidin protein blotting technique. J Immunol Methods 85, 195-202.

Jensen, R. G. (1995). Vitamins in milk. B. Water-soluble vitamins in bovine milk. In Handbook of Milk Composition, pp. 688-692. Edited by R. G. Jensen. San Diego, CA: Academic Press.

Johnson, D. A. \& Elder, J. H. (1983). Antibody directed to determinants of a Moloney virus derived MCF GP70 recognizes a thymic differentiation antigen. J Exp Med 159, 1751-1756.

Kandasamy, R., Vediyappan, G. \& Chaffin, W. L. (2000). Evidence for the presence of Pir-like proteins in Candida albicans. FEMS Microbiol Lett 186, 239-243.

Klotz, S. A. \& Smith, R. L. (1991). A fibronectin receptor on Candida albicans mediates adherence of the fungus to extracellular matrix. J Infect Dis 163, 604-610.

Laemmli, U. K. (1970). Cleavage of structural proteins during assembly of the head of bacteriophage T4. Nature 227, 680-685.

Leong, M. M. L., Milstein, C. \& Pannell, R. (1986). Luminescent detection method for immunodot, Western and Southern blots. $J$ Histochem Cytochem 34, 1645-1650.

Marot-Leblond, A., Robert, R., Loiseau, O., Apaire-Marchais, V. \& Senet, J. M. (2000). Hydrophobic and hydrophilic cell surface (glyco)proteinic components of Candida albicans. J Mycol Med 10, 115-122.

Mrsă, V., Seidl, T., Gentzsch, M. \& Tanner, W. (1997). Specific 
labelling of cell wall proteins by biotinylation. Identification of four covalently linked O-mannosylated proteins of Saccharomyces cerevisiae. Yeast 13, 1145-1154.

Nègre, E., Vogel, T., Levanon, A., Guy, R., Walsh, T. J. \& Roberts, D. D. (1994). The collagen binding domain of fibronectin contains a high affinity binding site for Candida albicans. J Biol Chem 269, 22039-22045.

Odds, F. C. (1988). Candida and Candidosis. A Review and Bibliography, 2nd edn. London: Baillière Tindall.

Pastor, F. I. J., Valentín, E., Herrero, E. \& Sentandreu, R. (1984). Structure of the Saccharomyces cerevisiae cell wall mannoproteins released by zymolyase and their contribution to wall architecture. Biochim Biophys Acta 802, 292-300.

Reiss, E., Hearn, V. M., Poulain, D. \& Shepherd, M. G. (1992).
Structure and function of the fungal cell wall. J Med Vet Mycol 30, 143-156.

Singleton, D. R., Masuoka, J. \& Hazen, K. C. (2001). Cloning and analysis of a Candida albicans gene that affects cell surface hydrophobicity. J Bacteriol 183, 3582-3588.

Sternberg, S. (1994). The emerging fungal threat. Science 266, 1632-1634.

Towbin, H., Staehelin, T. \& Gordon, J. (1979). Electrophoretic transfer of proteins from polyacrylamide gels to nitrocellulose sheets: procedure and some applications. Proc Natl Acad Sci US A 76, 4350-4354.

Received 4 September 2001; revised 25 November 2001; accepted 5 December 2001. 